\title{
Cut Layer Rocky Landslide Development Mechanism in Lesser Khingan Mountain
}

\section{$\operatorname{AUTHOR}(\mathrm{S}):$}

Jiang, Hua; Hu, Zhaoguang; Guo, Ying; Wang, Chunjiao; Shan, Wei

\section{CITATION:}

Jiang, Hua ... [et al]. Cut Layer Rocky Landslide Development Mechanism in Lesser Khingan Mountain. Kyoto Conference Proceedings (The Tenth International Symposium on Mitigation of Geo-disasters in Asia 2012: 36-44: 共同研究（一般研 究集会) 24K-02

ISSUE DATE:

2012-10-07

URL:

http://hdl.handle.net/2433/180437

RIGHT: 


\title{
Cut Layer Rocky Landslide Development Mechanism in Lesser Khingan Mountain
}

\author{
Hua Jiang, Zhaoguang Hu, Ying Guo, Chunjiao Wang \\ and Wei Shan
}

\begin{abstract}
Bei'an to Heihe expressway utilizes the original second-class highway to widen and expand for expressway, restricted by the original location of old road, widen subgrade of some sections locate in tailing edge of the landslides, influenced by the landform, geological condition, climate and anthropogenic factors, are in unstable states, bring great difficulties to widening and expanding implementation. In process of landslide researching, firstly identify the space form of landslide, analyze the formation mechanism of landslide, evaluate the stability condition and the development tendency of landslide, and then determine the prevention and treatment measures. Took the Bei' an to Heihe expressway cut layer rocky landslide as the research object, employed the geological survey, topographic mapping, geological drilling, indoor test, numerical simulation, field monitoring and theoretical analysis methods to carry an integrated study on the development mechanism and damage mode of the landslide. Through systematic study, drew the conclusions that: the rupture surface is located in completely weathered mudstone; during surveying, the landslide is temporarily in steady state, when the water content continues to increase to $34.7 \%$, the landslide will reach the state of limit equilibrium; atmospheric precipitation, the island permafrost which scattered in the mountain valley melting water, snowmelt water and seasonally frozen soil thawing water provide a continued water source for landslide, surface water and ground water supply the Cretaceous pore water by infiltration and lateral runoff through surface thermal shrinkage cracks and shallow high permeability rock and soil, low permeability mudstone under the loose overburden forms aquiclude,
\end{abstract}

Wei Shan (1965), male, professor, doctor of Engineering, doctoral tutor. Research interests: disaster prevention and mitigation of road and bridge engineering.

H. Jiang $\cdot$ Z. Hu $\cdot$ Y. Guo $\cdot$ C. Wang $\cdot$ W. Shan $(\bowtie)$

Northeast Forestry University, 150040 Harbin, China

e-mail: shanwei456@163.com 
completely weathered mudstone above the aquiclude which is influenced by the Cretaceous pore water to be soften forms rupture surface; due to the permafrost distribution discontinuities and geological conditions difference, the landslide has gradual, low angle, creeping characteristics.

Keywords Expressway - Cut layer rocky landslide - Development mechanism • Damage mode

\section{Introduction}

Landslide is a phenomenon that the rock and soil of a slope occurs shear failure and significant horizontal displacement along a weak structural zone or maximum shear zone (Hu and Wang 2010; Qiao 2002). Landslide geological disasters have a wide distribution in the world, hazard is very serious, and it not only brings a threat to the safety of human life, but also has a destructive effect on the property, environment, and resource (Zhang et al. 2010). Bei'an to Heihe expressway utilizes the original second-class highway to widen and expand for expressway in Heilongjiang province of China, restricted by the original location of old road, some widen subgrade of $\mathrm{K} 177+400-\mathrm{K} 180+000$ section which is situated in the Lesser Khingan Mountain central region locate in tailing edge of the landslides(see Fig. 1), influenced by the landform, formation lithology, geological structure, hydrogeology condition, climate and anthropogenic factors (Duan 1999; Zhang et al. 2000; Li et al. 2002), the landslides are in unstable states, bring great difficulties to widening and expanding implementation.

In process of landslide researching, firstly identify the space form of landslide, analyze the formation mechanism of landslide, evaluate the stability condition and the development tendency of landslide, and then determine the prevention and treatment measures. This article took the Bei'an to Heihe expressway cut layer rocky landslide as the research object, employed the geological survey, topographic mapping, geological drilling, geophysical exploration, indoor test, numerical simulation, field monitoring and theoretical analysis methods to carry an integrated study on the development mechanism and damage mode of the landslide.

\section{Field Survey}

Bei'an to Heihe expressway landslide section is located in the central region of Lesser Khingan Mountain. The climate of the area belongs to continental monsoon climate, the spring gets warm quickly, the summer is tepidity and rainy, the 


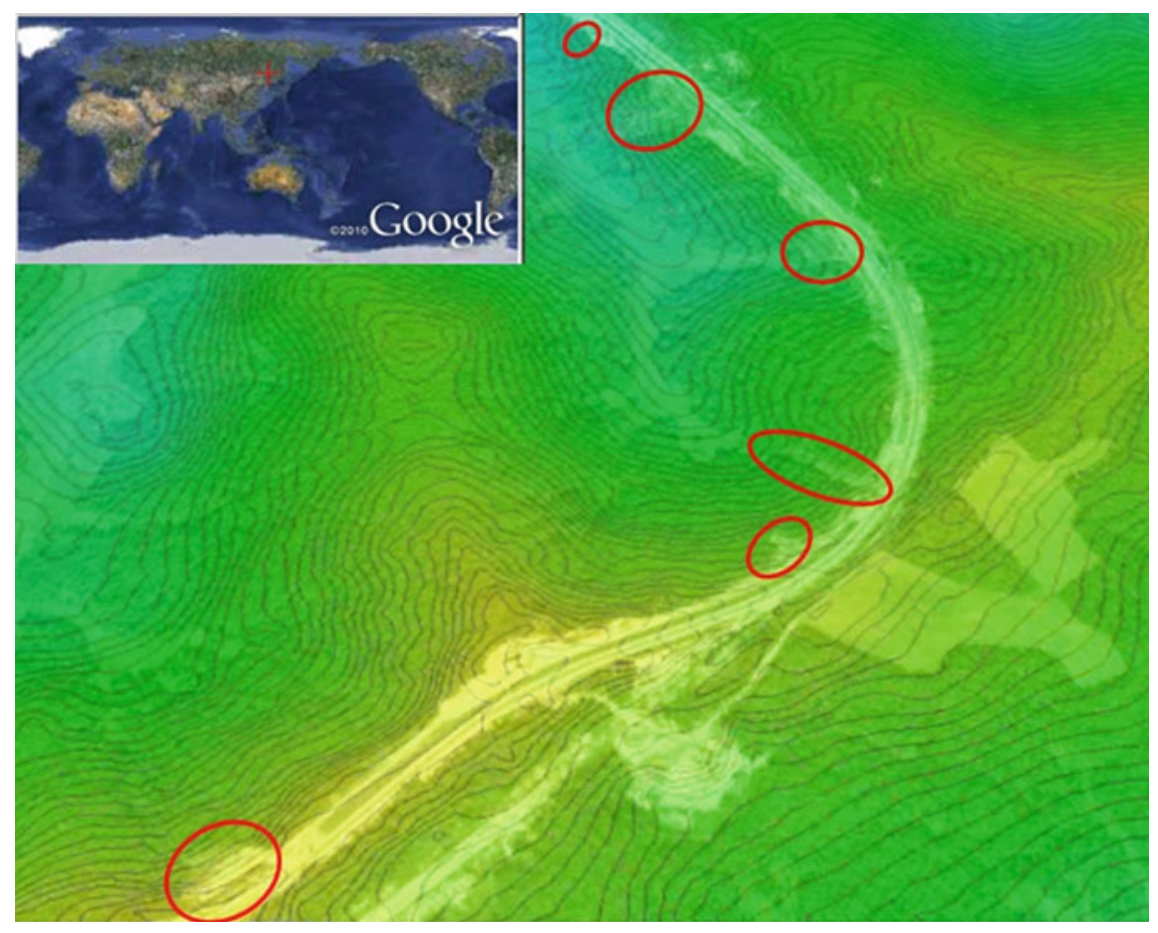

Fig. 1 Aerial view of Bei' an to Heihe expressway landslide section

autumn gets cool fast, the winter is long and cold. The annual average temperature is $-0.6{ }^{\circ} \mathrm{C}$. The average annual precipitation is $400-650 \mathrm{~mm}$, and the rainfall concentrates in July to September of the summer. Average sunshine time is 2551.5 h. Frost-free period is 90-120 days.

The tectonic is in the Wuyun-Jieya new rift zone, the south is Shuhe upwarping zone and the north is Handaqi virgation. Surface exposed stratum: the upper Cretaceous Nenjiang formation, Tertiary Pliocene series Sunwu formation, and Quaternary Holocene series modern river alluvium and stack layers. According to the aquiferous medium, supply and drainage conditions, groundwater is divided into Cretaceous pore water, Tertiary pore water and Quaternary pore water three kinds.

According to the field survey, found three sections widening subgrade influenced by landslide, this article aimed at the first landslide, the landform of the landslide is shown in Fig. 2.

The whole landform of landslide area is one ridge at the back, two ridges on the left and right sides, gentle slope terrain in the middle part. The flat shape of landslide body presents a tongue. There are inconspicuous arc cracks on the tailing edge of the landslide, upheaval on the front of the landslide and scaly turf on the surface of the landslide body (see Fig. 2). 


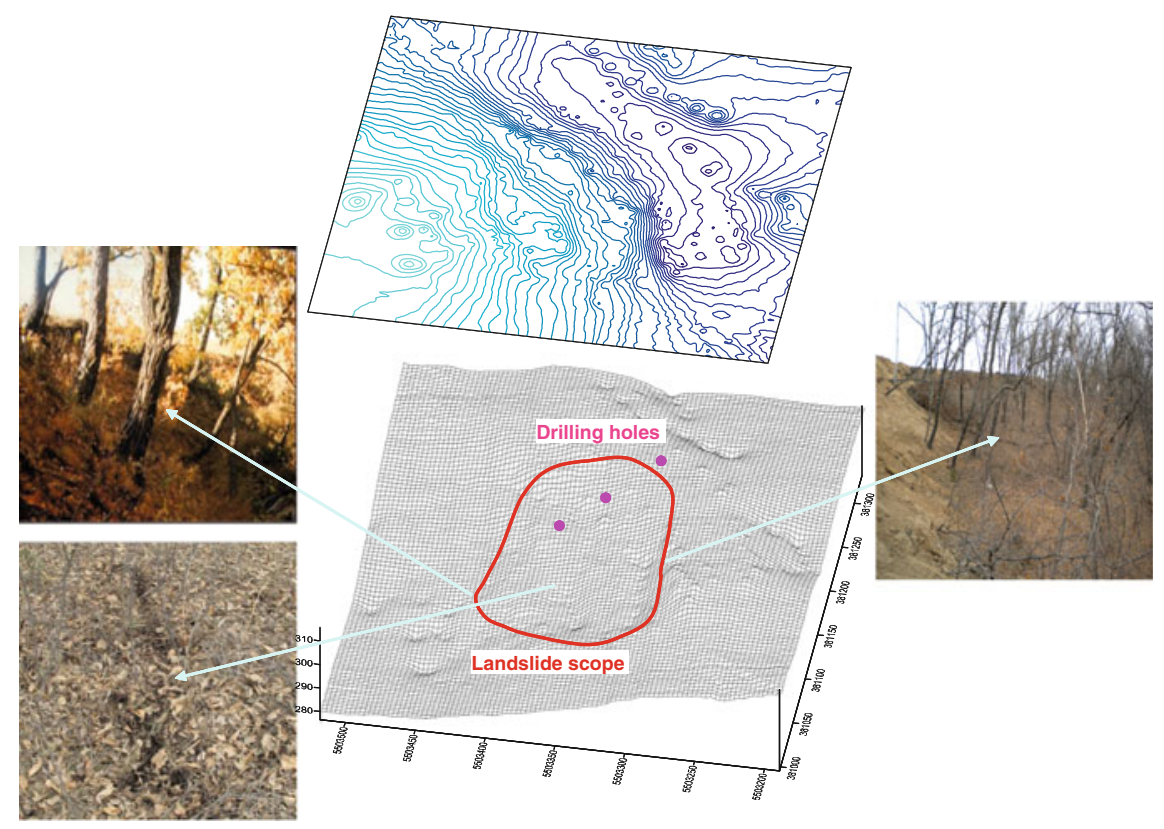

Fig. 2 Tree dimensional terrain of landslide region

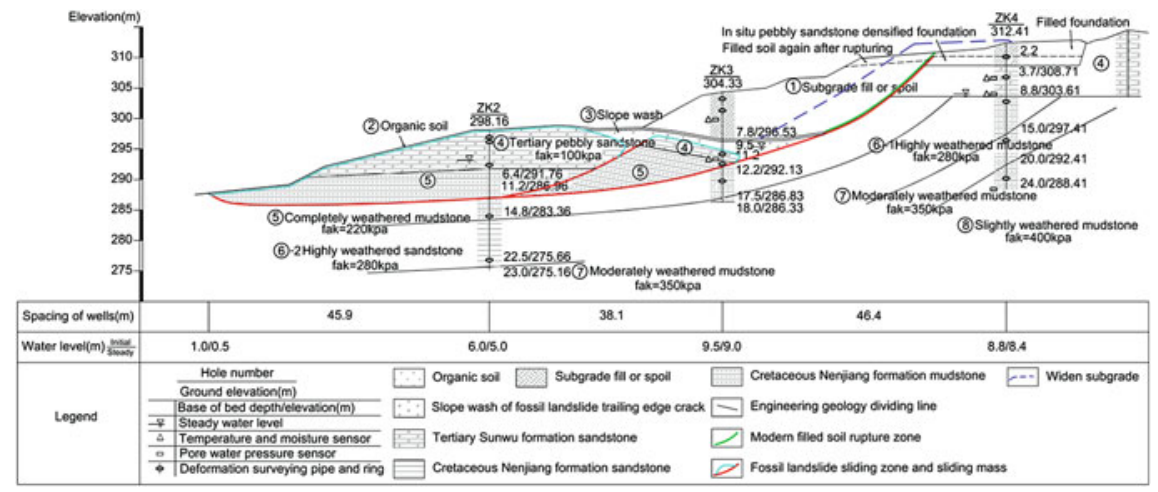

Fig. 3 Landslide engineering geological profile and monitoring equipment arrangement diagram

\section{Geological Exploration}

To survey the geological condition of the landslide, we arranged three drilling holes and five resistivity measure lines, drilling holes position as shown in Fig. 2. According to the drilling and resistivity surveying results, drew the engineering geological profile as shown in the Fig. 3. Deformations monitoring equipments, 
temperature, moisture, pore water pressure sensors were respectively embedded in the holes.

The surface of landslide area mainly consists of Tertiary pebbly sandstone and subgrade abandon soil (sandy clay), high void ratio, many cracks in the soil and weak integrity. The shallow completely weathered mudstone has obvious cracks which have evident water encroached signs; the deep completely weathered mudstone is relatively dense. Through indoor test, the permeability coefficient of sandy clay is $2.74 \times 10^{-6} \mathrm{~m} / \mathrm{s}$, Tertiary pebbly sandstone is $2.55 \times 10^{-5} \mathrm{~m} / \mathrm{s}$, shallow completely weathered mudstone is $1.74 \times 10^{-6} \mathrm{~m} / \mathrm{s}$, and deep completely weathered mudstone is $2.23 \times 10^{-7} \mathrm{~m} / \mathrm{s}$.

The permeability coefficient of surface rock and soil and shallow completely weathered mudstone is larger, the permeability coefficient of deep completely weathered mudstone is smaller. When the water penetrates downward through shallow rock and soil and accumulates on the surface of the dense mudstone, the water content of the mudstone layer increased gradually, shear strength decreases significantly. This judgment, the landslide belongs to cut layer rocky landslide, rupture surface is located in completely weathered mudstone.

\section{Landslide Stability Numerical Simulation}

Limit equilibrium method is the most mature method in landslide stability study (Liu et al. 2007; Hu et al. 2005). The limit equilibrium method is characterized in that only considers static equilibrium condition and soil Mohr-Coulomb failure criterion, need assume rupture surface during calculating. Compared with limit equilibrium, finite element method namely considers the soil static equilibrium, also meets the strain compatibility and stress strain constitutive relation, can serve as a more rigorous theoretical system for slope stability analysis, it needn't assume the shape and position of rupture surface, determines the stability of landslide through stress and strain analysis (Yang et al. 2010; Zhu et al. 2007).

Through geological survey and indoor test analysis, the landslide stability is mainly controlled by the water content of rupture surface rock and soil, employed finite element method to study the law that safety factor of landslide changes with water content of rupture surface soil. The finite element calculation parameters of rock and soil were determined by indoor experiment and engineering analogy method, as shown in Table 1.

The rupture surface soil water content is $32.1 \%$ and saturation is 0.899 during surveying, the slope safety factor is 1.58 , the landslide total deformation before damage is shown in Fig. 4. The landslide is temporarily in a steady state, but the rupture surface soil has not reached saturation state, when the water content of the rupture surface soil continues to increase to $34.7 \%$, saturation reaches 0.972 , the safety factor of landslide will be reduced to 1.08, and the landslide will reach the state of limit equilibrium. When the surface soil saturated with water or 
Table 1 Physical and mechanical parameters of calculation model

\begin{tabular}{|c|c|c|c|c|c|}
\hline Rock and soil name & $\begin{array}{l}\text { Unit } \\
\text { weight } \\
\left(\mathrm{g} / \mathrm{cm}^{3}\right) \\
\end{array}$ & $\begin{array}{l}\text { Cohesion } \\
(\mathrm{kPa})\end{array}$ & $\begin{array}{l}\text { Friction } \\
\text { angle } \\
\text { (degree) }\end{array}$ & $\begin{array}{l}\text { Modulus of } \\
\text { elasticity } \\
\text { (MPa) }\end{array}$ & $\begin{array}{l}\text { Poisson's } \\
\text { ratio }\end{array}$ \\
\hline Subgrade fill or spoil & 1.89 & 21 & 9 & 14 & 0.35 \\
\hline Pebbly sandstone & 1.98 & 5.2 & 27 & 26 & 0.22 \\
\hline $\begin{array}{l}\text { Completely weathered mudstone } \\
\text { above the rupture surface } \\
\text { (natural/saturated) }\end{array}$ & $\begin{array}{r}1.81 / \\
1.85\end{array}$ & $16.4 / 10.3$ & $8 / 5$ & $15 / 15$ & $0.36 / 0.36$ \\
\hline $\begin{array}{l}\text { Completely weathered mudstone } \\
\text { under the rupture surface }\end{array}$ & 1.80 & 26.6 & 12 & 32 & 0.35 \\
\hline $\begin{array}{l}\text { Highly weathered mudstone and } \\
\text { sandstone }\end{array}$ & 1.85 & 34.7 & 14 & 70 & 0.34 \\
\hline Moderately weathered mudstone & 1.88 & 45.5 & 18 & 93 & 0.32 \\
\hline Slightly weathered mudstone & 1.91 & 57.6 & 19 & 110 & 0.3 \\
\hline
\end{tabular}

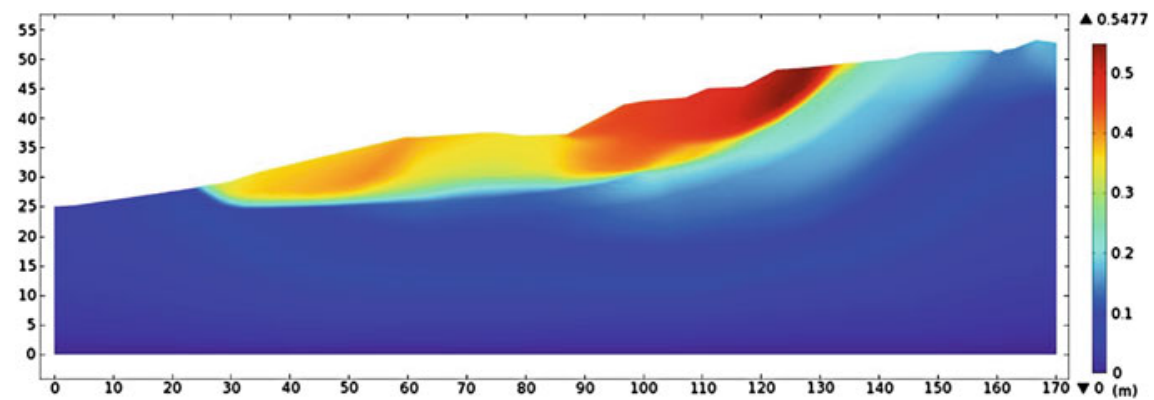

Fig. 4 Landslide total deformation cloud map before damage

abandon soil loading or filling subgrade, the ancient landslide will be likely to slide, and affect the stability of subgrade slope.

\section{Field Monitoring}

After surveying, we began to collect monitoring data, 32 days later, found that ZK2 and ZK3 deformation monitoring pipe were sheared respectively in the depth of $11.0 \mathrm{~m}$ and $12.1 \mathrm{~m}$ under the original ground; the temperature, moisture and pore water pressure sensor connections were also sheared; striation appeared on the front of the landslide; many cracks appeared on the mountain surface, and the cracks were in developing trend. Based on these data and phenomena, judged that the slope occurred slide. At that same time, employed GPS to monitor the tube nozzle moving data (see Fig. 5), and paid attention to the pore water pressure data 


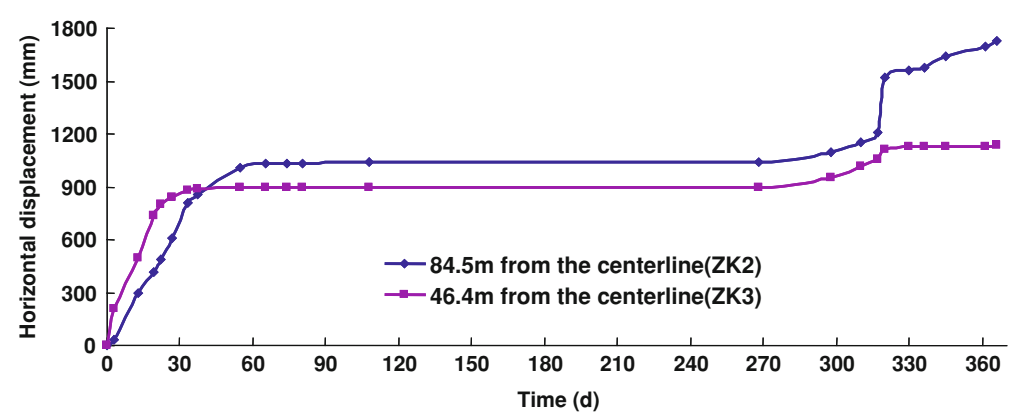

Fig. 5 Curve of nozzle horizontal displacement changes with time

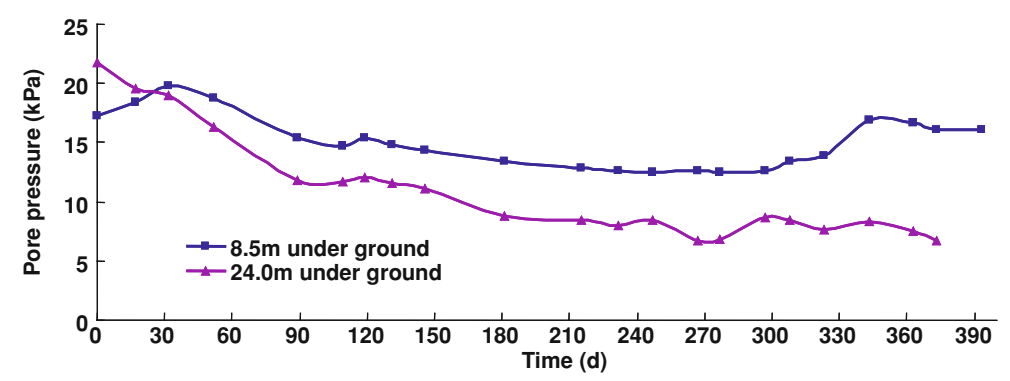

Fig. 6 Curve of ZK4 pore water pressure changes with time

(see Fig. 6) and deformation data of ZK4, the vertical and horizontal displacement of ZK4 were very small.

The landslide began to slide at the rainy season, deep pore water pressure of the region was max of the year, and reached the steady state until winter when the ground began to freeze, the maximum horizontal displacement respectively reached 1.03 and $0.9 \mathrm{~m}$, the landslide formation is mainly influenced by precipitation and permafrost melting. The landslide slid again in the spring melts period of the following year, the seasonal frozen soil layer of the area was completely melted at that time, deep pore water pressure increased rapidly, and the maximum horizontal displacement respectively reached 1.73 and $1.14 \mathrm{~m}$, landslide sliding again is mainly influenced by frozen soil melting and snowmelt.

\section{Landslide Development Mechanism}

Formation and development of the landslide is mainly affected by the landform, climate and water, geological condition and other factors.

Topography condition: topography of the landslide is upper steep and lower gentle, one ridge at the back, two ridges on the left and right sides, is avail for 
Fig. 7 Landform vector graph of landslide region

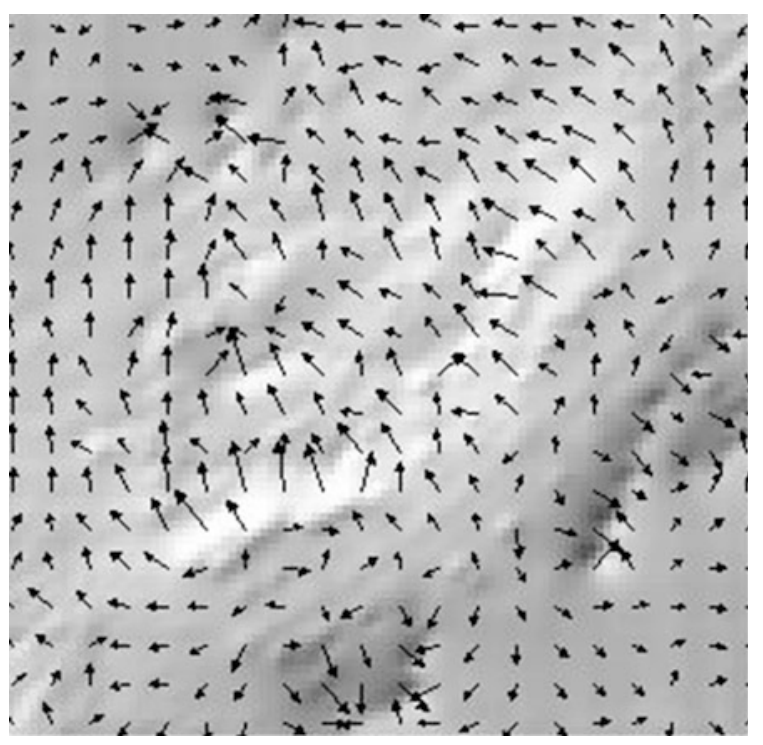

surface water and ground water to assemble in landslide (see Fig. 7); the rupture surface is so gentle to retain rainwater for a long time; these provide favourable terrain condition for the landslide development.

The effect of climate and water: atmospheric precipitation and permafrost melting water constantly supply the Cretaceous pore water in the rainy season, snowmelt water and seasonally frozen soil thawing water constantly supply the Cretaceous pore water in the spring thawing period. Under the action of water, unit weight of the slide body increases and shear strength of rupture surface soil decreases.

Geological condition: surface thermal contraction cracks and shallow high permeability soil and rock provide infiltration and lateral runoff channel for surface water and ground water; low permeability mudstone under the loose overburden forms aquiclude, completely weathered mudstone above the aquiclude which is influenced by the Cretaceous pore water to be saturated, the shear strength of the completely weathered mudstone decreases dramatically, then induce the landslide instability.

\section{Conclusions}

This article employed the geological survey, topographic mapping, geological drilling, geophysical exploration, indoor test, numerical simulation, field monitoring and theoretical analysis methods to carry an integrated study on the development mechanism and damage mode of the Bei' an to Heihe expressway cut layer rocky landslide, drew the conclusions that: 
The landslide belongs to cut layer rocky landslide, and the rupture surface is located in completely weathered mudstone.

During surveying, for the rupture surface completely mudstone, the water content is $32.1 \%$, the landslide is temporarily in steady state, when the water content continues to increase to $34.7 \%$, saturation reaches 0.972 , the safety factor of the slope will be reduced to 1.08 , and the landslide will reach the state of limit equilibrium.

Atmospheric precipitation, the island permafrost which scattered in the mountain valley melting water, snowmelt water and seasonally frozen soil thawing water provide a continued water source for landslide, surface water and ground water supply the Cretaceous pore water by infiltration and lateral runoff through surface thermal shrinkage cracks and shallow high permeability rock and soil, low permeability mudstone under the loose overburden forms aquiclude, completely weathered mudstone above the aquiclude which is influenced by the Cretaceous pore water to be soften forms rupture surface.

Due to the permafrost distribution discontinuities and geological conditions difference, the landslide has gradual, low angle, creeping characteristics.

Acknowledgments This work was financially supported by Heilongjiang Communications Department project and subtopic of the western communication science and technology project "Study on Subgrade Stability Controlling Technology of Expressway Expansion Project Permafrost Melt and Landslides Sections".

\section{References}

Duan YH (1999) Basic characters of geo-hazards and its development trend in China. Quaternary Sci 19(3):208-216

Hu RL, Wang SS (2010) Main feature and identification method of sliding-surfaces in soil and rock slopes. J Eng Geol 18(1):35-40

Hu XW, Tang HM, Liu YR (2005) Verification of transfer coefficient method applied to landslide stability analysis by physical model test. Rock Soil Mech 26(1):63-66

Li YH, Zhang XY, Cui ZJ (2002) Periodic coupling of debris flow active periods and climate periods during Quaternary. Quaternary Sci 22(4):340-347

Liu HL, Zhu DY, Liu DF (2007) Discussion on multiple solution of safety factor of a slope. Rock Soil Mech 28(8):1661-1664

Qiao JP (2002) Structure and shape of landslide. Chin J Rock Mech Eng 21(9):1355-1358

Yang T, Zhou DP, Ma HM (2010) Point safety factor method for stability analysis of landslide. Rock Soil Mech 31(3):971-975

Zhang CS, Zhang YC, Hu JJ (2000) Spatial and temporal distribution characteristics and forming conditions of Chinese geological disasters. Quaternary Sci 20(6):559-564

Zhang LM, Zheng MX, He M (2010) Study of characteristics of matric suction in landslide slip soils before and after landslide control. Rock Soil Mech 31(10):3305-3312

Zhu YS, Li HL, Cao NE (2007) Finite element method research on road slide stability analysis. J Highw Transp Res Dev 24(4):39-42 